\title{
The Organization of an Audio-Visual Unit in a Junior College Library'
}

Mr. Peskind is Director, Audio-Visual Department, Wright Junior College, Chicago.

$\mathrm{O}$ NE of the recent and significant developments of education at the junior college level has been the rapid expansion in the use of audio-visual materials. Because these materials cover a tremendous range of types, it is necessary for purposes of discussion to define what may be considered audiovisual materials at the junior college level. Audio-visual materials at this level do not mean what audio-visual materials at the university level mean. Therefore, there are not included, at this time, those materials and equipment which preserve learning such as microfilms and microcards. Though they have great usefulness for the junior college library, their very nature makes them especially appropriate for the purposes of the large four-year college and university library.

What I shall include as audio-visual at this time are those materials which require special technical devices, involving modern techniques of communication, and which are unusually adaptable for purposes of instruction at the junior college level. This does not mean that materials which are not mentioned are not audio-visual and that these other materials are not appropriate to the junior college level. It merely means that they are outside the present limits of discussion.

1 Paper presented at the meeting of the Junior College Libraries Section, A.C.R.L., Cleveland, July 19, I950.
Virtually no one will ask why we should have audio-visual materials. But when one asks why put these materials in the library, the problem becomes more complex. Almost everyone actively engaged in the audiovisual field insists that services and materials should be centrally administered, but few who are not librarians will concede that they belong in the library. It may be observed that audio-visual materials and printed materials serve identical purposes and for that reason should be organized and correlated in a single program. A library is technically set up, as no other organization is, for the functions of acquisition, processing and cataloging, all vital in audio-visual organization. There are other reasons for the inclusion of such a program in the library, but the purpose here is to explain how one can function.

The problem may be stated as follows: If an audio-visual unit is considered necessary for a junior college library, what kind of unit should be organized? The answer is, of course, that the situation is relative, depending upon the particular junior college, the library, the people in both, the financial resources and the existing audiovisual program. The kinds of organization that may result are numerous. It may be necessary for the library to divide audiovisual responsibility with the instructional departments or with an already existing centralized unit. It would be advantageous in such a situation for the library to be the agency to house, organize and distribute materials. But best of all is to have the library administer the entire program. 
To start an audio-visual unit, the librarian may have to initiate all moves from convincing the faculty and administrators to the actual establishment of the unit. A preliminary survey of the situation should consider staff, budget, existing programs and personal conflicts. However, in planning, a good rule to follow is: find the absolute limit of your capacity to absorb audio-visual functions and then go twice as far!

What functions should the audio-visual unit assume? Or what functions can it assume? A description of certain aspects of an existing junior college library audiovisual unit may help to answer these questions. Although this unit is now only in an early stage of development, it is being described because the scope of its operations is within the realm of possibility for other junior college libraries.

\section{Background and Physical Characteristics}

This particular audio-visual unit is one that was organized during the early months of 1950 in the Wright Branch of the Chicago City Junior College. This branch normally has a regular student enrollment of over 5000 and an additional 1500 or more adult education registrants.

The physical plant consists of one very large building, constructed in 1934, and one which, comparatively speaking, may be called well-equipped though its facilities are very overcrowded. The library, in which the audio-visual unit was placed, is located in one extremely large rectangular room divided vertically to separate the various functional divisions of the library.

Before the library unit was initiated, each instructional department had its own audiovisual equipment and materials. When the junior college administration decided upon a centralized audio-program, each department was asked to participate in the centralization by voluntarily contributing its equipment and materials to the library. Equipment and materials which were more conveniently located in the individual departments, or which were thought to be more useful decentralized, were left in the departmental rooms and offices. There was nothing arbitrary in the centralization change over.

The basic policy and raison d'etre of the audio-visual program are to relieve faculty members of the necessity of dealing with technical complexities when using audiovisual aids so that they are left free to concentrate on the all-important utilization factor in teaching.

With this policy in mind, the librarian set out to incorporate an audio-visual program within the framework of the library organization.

The assistant librarian was made director of the new program and was given complete responsibility over all phases of its administration. Library clerks were appointed and trained for the new routines and technically-minded students were hired for operation, messenger and repair work. Technical knowledge of a more expert sort was gathered from existing resources on the college faculty. The audio-visual director has retained his assistant-librarian status but the audio-visual function occupies virtually all of his time. Audio-visual finances have become part of the library budget and the junior college has generously increased appropriations to the library accordingly.

An audio-visual room was carved out of the library, and in it were placed tables and chairs for over 30 students or faculty members to listen to phonographs and to use other equipment. In an adjacent room, all other equipment and replacement parts are housed so that they may be ready for circulation at any time. Phonograph record cabinets, film and filmstrip cabinets, slides and other materials are kept in the audio-visual 
room. Books on the audio-visual subject, vertical files containing film catalogs and other materials, the audio-visual periodicals and reference books are also kept here for convenient usage. The desks of the audiovisual director and his assistants are kept in the new room to make it a convenient and compact center for the implementation of a large audio-visual program.

\section{Equipment and Materials}

By the end of June I950, the supply of equipment and materials had grown considerably. There were five motion picture projectors, an auditorium projector, three $3 \frac{1}{2}$ " $\times 4^{\prime \prime}$ slide projectors, two $2^{\prime \prime} \times 2^{\prime \prime}$ slide projectors, two filmstrip projectors, four portable phonographs, a turntable capable of playing records through the auditorium, gymnasium and other amplifiers, Io listening stations for the library capable of having six students listening at each station through earphones, two viewers for 2 " $\mathbf{x}^{\prime \prime}$ slides for library use by students, an overhead projector, an opaque projector, a large disc recorder, a tape recorder, as well as a small portable tape recorder, and numerous screens, tables, stands, lenses, replacement parts and other supplies. Though this collection of equipment has grown very rapidly and very efficient usage has been attempted, indications are that more equipment will certainly be needed to meet current demands.

The audio-visual room contains over 3000 phonograph records, all purchased recently, one-fourth being 33 I/3 long-playing types. The rapidly expanding motion picture film cabinets now house over 100 films and filmstrips, slides and transcriptions; other materials are accumulating rapidly. Care is taken in selecting these materials, with faculty members ordering only items meeting their high standards for acquisition. Since they are familiar with sources, the library staff cooperates in selection.
Functions and Services of the Audio-Visual Unit

I. Reference and information services: With the collections of books, pamphlets, periodicals and other materials on the audiovisual subject housed in the audio-visual room, the director is able to provide a reference service for faculty members. Information on suitable materials is given whenever it is requested. It is often necessary to phone other libraries and film information centers to provide the required information, but this service is considered a necessary function in the new unit. Lists of new materials are sent to faculty members and previews are always arranged when interest in any material is evident.

2. Acquisition, processing and cataloging of materials: The library unit is responsible for acquiring all audio-visual materials needed by the college. Films are normally rented but are purchased when continued usage shows that permanent acquisition is more economical than frequent rentals. A delivery service is provided by the library for rental pickups, and close contact is maintained with all film rental agencies in Chicago. Films and other materials are inspected, dated and labeled when they arrive and care is taken to see that rented materials are returned at the proper time. All audiovisual materials which are part of the library's permanent collection are cataloged and incorporated into the card catalog. Numerous subject headings and other entries have been devised so that maximum usage of audio-visual materials can be made through information from the card catalog.

3. Circulation of audio-visual materials and equipment: All materials and equipment are circulated anywhere within the college. Students are free to use any materials within the library and phonograph records are on open shelves to be taken and used as freely as books or periodicals. Cer- 
tain materials are circulated for home use if faculty members request that they be available in this manner. The audio-visual unit also circulates, without restriction, maps, pictures, posters, display letters and cases, etc., to all persons requesting them.

4. Adapting college plant for audio-visual usage: The furthering of better physical facilities for audio-visual use in the college has been a continual function of the new unit. It has been felt that the best possible conditions for projections must be obtained if they are to be shown at maximum efficiency and usefulness for teaching. Almost every room in the building has been equipped with darkening shades, additional electrical outlets and other helpful devices.

5. Operation of equipment within the college: To arrange a projection or other audio-visual function in his classroom, the faculty member at Wright informs the library unit of the room number, date and time of his class meeting and the materials that he will use. The necessary equipment and materials are brought to the class meeting at the proper time and operated by a library operator who later returns the equipment and materials to the library. Early requests are, of course, encouraged but for public relations purposes, all requests are acknowledged regardless of the lateness of the hour or of the inconvenience to the library.

6. Maintenance and repair of equipment : Technically-minded students have been trained to keep the projectors and other equipment oiled, cleaned and in the best possible working condition. These assistants have also been found capable of making minor and sometimes major repairs on most equipment.

7. Research in the development of new equipment or special adaptation of old equipment for the best utilization of audiovisual materials: The audio-visual director frequently consults with sound engineering agencies, film projection specialists, as well as engineering specialists on the Wright faculty, to develop newer improved equipment. This procedure has resulted in the exceptionally satisfactory listening stations, earphone inputs for the tape recorders and motion picture projectors, convenient control boards for the auditorium and special lenses and sound jack boxes for projectors. It has been discovered that many types of standard equipment can be made much more useful for specific purposes through minor adaptations or changes.

8. Training of faculty and students in the use of audio-visual equipment and materials: A primary function of the audiovisual unit is to train persons to be skillful in the operation and use of machines and materials. Faculty members who wish to operate the equipment themselves are given instructions. Students using the phonographs, slide and film-strip projectors, tape recorders or other equipment are carefully instructed in proper usage.

9. Integrating audio-visual usage into the curriculum through cooperation with the faculty: Considerable attention is paid to distributing information to faculty members as to how audio-visual materials may be used in their courses. The audio-visual director sometimes arranges to speak at departmental faculty meetings for the purpose of disseminating information about audiovisual materials. Faculty members are encouraged to discuss audio-visual utilization problems with the audio-visual director.

Io. Production of audio-visual materials: The library unit cooperates with the Physical Science Division and their associated photographic laboratory in producing films, filmstrips and slides for instructional use. In the field of sound reproduction, the audio-visual unit cuts and dubs phonograph records and produces tapes upon request. Unusually difficult requests are sent to pro- 
fessional recording agencies. An interesting application of sound reproduction in the unit was initiated when secretarial practice teachers recorded their voices at various speeds so that students could practice taking dictation at those speeds in the library and at home.

I I. Services of a noninstructional nature : The library's audio-visual service is not confined to instructional purposes alone. Many students who crowd the audio-visual room every day to listen to the fine music and drama recordings are there not because of compulsory class assignments but because they have an opportunity to listen to fine music and drama not easily available elsewhere. Music, films, etc. are available to student organizations. A student club of New Orleans jazz enthusiasts, for example, use the library disc recorder to dub copies of rare recordings for distribution to each of the club members. Service is also provided to college play productions, athletic events, concerts, etc.

It is impossible to evaluate objectively the audio-visual program at this junior college. The program has not been in existence long enough. A great deal, however, has been achieved in this short period. There has been some confusion and there is a question of providing too much. An overabundant energy devoted to audio-visual service might detract from the traditional library service, but care has been taken in limiting the program so that dangers in these directions are slight. Faculty and student reaction has been one of singular enthusiasm and this alone has been enough encouragement to continue developing the program.

It is difficult to describe how important this audio-visual program has been for the library and for the school. It has meant an efficient integration of audio-visual materials into the curriculum with little or no expense to faculty members' time wasted on its technical aspects. It has meant that students have begun to view the library as a place to find the best not only in books but also in art and music. It has meant that the library has taken steps to become the complete library, the library which provides the necessary variety in materials and services which teaching now requires.

It must not be forgotten that the junior college library performs one of its most effective roles within a junior college by being a service unit, and the more widespread and complete its services, the more effective and valuable is the library to the junior college it serves. By widening the scope of library operations, we are helping to make the library a more effective instrument for teaching at the junior college level.

\section{Correction}

In the article on "Investigations and Research Projects in the Field of College Libraries," October 1950 issue, p. 32I-27, footnote I9 should have read "Michigan" instead of "Denver" and footnote 60, "Michigan" instead of "Illinois." The date in footnote 13 should have been "I 875 " instead of "I $785 . "$ 